\title{
Teresa y Luis, Luis y Teresa. Dos santos en tiempos recios
}

\author{
Teresa and Luis, Luis and Teresa. Two saints in tiempos recios
}

\author{
Emilio Callado Estela \\ ecallado@uchceu.es
}

Universidad CEU - Cardenal Herrera

Resumen: El presente artículo analiza la relación entre dos grandes santos españoles de la Contrarreforma Católica, Teresa de Jesús y el dominico fray Luis Bertrán

Palabras clave: Teresa de Jesús, Luis Bertrán, Santos, Contrarreforma, Carmelitas Descalzos, Dominicos, Siglo XVI

Abstract: The present article analyses the relation between two big Spanish saints of the Catholic Counterreformation, Teresa de Jesus and the Dominican monk Luis Bertrán

Keywords: Teresa de Jesus, Luis Bertrán, Saints, Counter-reformation, Discalced Carmelite, Dominicans, 16th century 


\section{Emilio Callado. Teresa y Luis, Luis y Teresa. Dos santos en tiempos recios}

Teresa de Jesús perteneció a una generación irrepetible de hombres y mujeres marcada por la convulsión de la disensión religiosa que caracterizó los tiempos recios del Quinientos, y cuyo compromiso con la actividad reformadora, el celo apostólico y el amor por la Iglesia compartieron -desde espiritualidades distintas, pero con objetivos comunes- a través de una íntima amistad prolongada en muchos casos hasta el final de sus días. ${ }^{1} \mathrm{El}$ trato personal, directo o por medio de la correspondencia epistolar, fue el cauce habitual empleado por tales personajes, que imbuidos en el pensamiento de Cristo se comunicarían entre sí anhelos y frustraciones, a la búsqueda de comprensión y consejo en un tiempo de mudanza como el que les cupo en suerte, porque «todos somos de una misma librea» según sentenció uno de ellos. ${ }^{2}$ Una auténtica comunidad de santidad integrada por virtuosos modelos de vida que, después de padecer en la Tierra indecibles rigores por su forma de entender la fe, pasarían a la Eternidad enriqueciendo el santoral. De la misma formaría parte, junto a la propia abulense, algunos destacados protagonistas de la Historia de la espiritualidad barroca, como Pedro de Alcántara, ${ }^{3}$ Francisco de Borja ${ }^{4}$ o Juan de Ribera. ${ }^{5}$ No por más desconocido dejó de serlo también otro de los religiosos al que mayor estima profesó la Madre del Carmelo descalzo. Jamás coincidieron personalmente, pese a testimoniarse ambos su afecto y devoción mutuas. Hablamos del dominico fray Luis Bertrán, hijo del convento de Predicadores de Valencia, destino varias veces frustrado - no se olvide- en los itinerarios teresianos y semillero de santos, beatos y venerables para la Monarquía Hispánica y el orbe católico entero durante la Contrarreforma (Cárcel Ortí 2001).

Al ocuparse de la santidad de Teresa de Jesús - muy devota, por cierto, del Patriarca de Caleruega y Catalina de Siena-, sostienen los historiadores de la orden de Predicadores que, bien desde el confesionario o desde otros lugares, «fueron los preclaros hijos de santo Domingo de Guzmán despertadores de su virtud y alentadores de la mejora y renovación de su espíritu». ${ }^{6}$ Opinión compartida por los biógrafos teresianos:

1 Estas líneas se incluyeron en el trabajo más extenso sobre las relaciones de Teresa de Jesús con algunos otros santos coetáneos. «Cuatro amigos. Teresa de Jesús, Francisco de Borja, Luis Bertrán y Juan de Ribera», en E. Callado Estela (enprensa).

2 En expresión de fray Pedro de Alcántara a la propia Teresa, según declaración de Pedro de Castro en el proceso de beatificación de esta última en Segovia (De Jesús 1951, I: 512). Damos más información después.

3 Véanse Santa María (1619), San Bernardo (1667) y Huerta (1669), entre otros.

4 Véanse las conocidas biografías de Ribadeneyra (1592), Schotto (1596), Cepari (1624), J. E. Nieremberg (1644) y Cienfuegos (1702). Más recientes, los trabajos de Suau (1963), Dalmases (1983) y García Hernán (1999).

5 Véanse los escritos de F. Escrivá (1612), Busquets Matoses (1683), Ximénez (1798), Belda (1802), Cubí (1912) y Robres Lluch (1960). De Teresa y Ribera nos ocupamos ya -además del trabajo citado en la nota 1- en Callado Estela (2009).

6 Así viene recogido en Martín (1909), Inciarte (1962) y Huerga (1963).

SCRIPTA, Revista internacional de literatura $i$ cultura medieval i moderna, núm. 7 / juny 2016 / pp. 150-159 ISSN: 2340-4841 · doi:10.7203/SCRIPTA.7.8474 


\title{
Emilio Callado. Teresa y Luis, Luis y Teresa. Dos santos en tiempos recios
}

Con los padres de la Compañía de Iesús no trató menos la santa madre que con los de la orden del glorioso santo Domingo. Que como en estas dos religiones veýa florecer tantas letras y tanto trato de oración y virtud, parecíales que yendo arrimada a la dotrina y enseñança dellos no sería engañada (Yepes 1601: s.p.)

Particularmente intensa fue la impronta dejada en nuestra protagonista por los padres Barrón, García de Toledo o Báñez. Sobre éstos y algunos otros la misma religiosa dio pormenorizada cuenta de nuevo en tercera persona:

\begin{abstract}
fray Vicente Varrón la confesó un año y medio en Toledo yendo a fundar allí, que era consultor de la Inquisición y gran letrado; éste la aseguró mucho. Y todos le decían que como no ofendiese a Dios y se conociese por ruín, que de qué temía. Con el maestro fray Domingo Vañes, que es consultor del Santo Oficio ahora en Valladolid, se confesó seis años, y siempre trata con él por cartas, cuando algo de nuevo se le ha ofrecido. Con el maestro Chaves. Con el segundo fue fray Pedro Iváñez, que era entonces lector en Ávila y grandísimo letrado. Y con otro dominico, que llaman fray García de Toledo. Con el padre maestro fray Bartolomé de Medina, catedrático de Salamanca, y sabía que estaba muy mal con ella, porque havía oído de estas cosas y parecióle que éste la diría mejor si iba engañada que nenguno ( esto ha poco más de dos años ); y procuróse confesar con él y diole larga relación de todo lo que allí estuvo, y procuró que viese lo que havía escrito para que entendiese mejor su vida. El la aseguró tanto y más que todos y quedó muy su amigo. También se confesó algún tiempo con el padre maestro fray Felipe de Meneses, que estuvo en Valladolid a fundar, y era el prior u rector de aquel colesio de San Gregorio; y haviendo oído estas cosas, la havía ido a hablar en Ávila con harta caridad quiriendo saber si estaba engañada y que si no era razón no la mormurasen tanto; y se satisfizo mucho. También trató particularmente con un Provincial de santo Domingo, llamado Salinas, hombre muy espiritual y gran siervo de Dios; y con otro lector que es ahora en Segovia, llamado fray Diego de Yanguas, harto de agudo ingenio (Martín 1909: 20-21).
\end{abstract}

Pero la lista de religiosos blanquinegros que influyeron en la doctrina, escritos y obra de la abulense quedaría incompleta sin el nombre de fray Luis Bertrán. Aunque más joven que Teresa, el citado fraile había forjado su reputación como estandarte de la reforma entre las filas del Patriarca de Caleruega. Nacido en Valencia allá por 1526, había vestido a los dieciocho años el hábito blanquinegro en el convento de Predicadores de esta ciudad, de la mano de otro icono del panteón dominicano, como fue el padre Juan Micó. Consagrado desde entonces a la labor apostólica desde los diferentes puestos de responsabilidad encomendados por la orden -maestro de novicios, prior y predicador entre ellos-, creó una auténtica escuela espiritual entre sus discípulos que trascendería a su propia muerte, tempranamente acaecida en $1581 .^{7}$

\footnotetext{
7 Entre las biografías clásicas sobre el personaje destacan Antist (1583) junto a las posteriores Addiciones (publicadas en Valencia, en 1593), Roca (1608), Aviñó (1623), Saborit (1651), Loarte (1672) y Vidal y Micó (1743). Remitimos, en cualquier caso, par amás información, a Callado Estela \& Esponera Cerdán (2008).
} 
No resulta extraño, pues, que en su intento de emprender la renovación del Carmelo la Santa recurriera al consejo de este fraile valenciano. La pregunta, no obstante, es cómo llegó a él. ${ }^{8}$ Desde luego pudo hacerlo a través de los propios dominicos castellanos, con presencia en la capital del Turia durante este período. El caso, sin ir más lejos, del padre Diego de Vitoria, hermano del gran teólogo Francisco, de igual apellido y amigo personal de fray Luis (Antist 1583: 156). Deben recordarse, asimismo, los vínculos con Castilla de éste último, frustrado alumno salmantino y conocedor de las corrientes espirituales de aquellas tierras (Robles Sierra 1973: 340-342).

Tampoco resulta descabellado que la vía de contacto entre Teresa y el padre Bertrán fueran los carmelitas. Dos de ellos, fray Miguel de Carranza y fray Damián León, tras visitar Valencia años atrás, habían hablado a la de Ávila de la observancia allí vivida por las monjas de la Encarnación. Un monasterio al que fray Luis, casualmente, andaba muy unido, pues en él solía predicar y mantener frecuentes coloquios espirituales con la popular madre Tejeda (Robles Sierra 1981: 121).

Algunos otros religiosos del Carmelo, además, eran íntimos del religioso, como los padres Juan Marcos o Bautista Fuser. En 1586 ambos depondrían su testimonio en el proceso informativo para la beatificación del dominico. El primero declaró «haber convivido con él [...] y que le había tratado en valencia y en Játiva [...] y por eso sabía que su vida había sido excelente y notable por la práctica de la religión cristiana y por su piedad» (Procesos... 1983: 234-235).

En idéntico sentido aseguró el segundo haber conocido a fray Luis, «y que por eso sabía que había llevado una vida excelente y notable por la práctica de la religión de Cristo y por la piedad» (Procesos... 1983: 236-237).

Claro que también pudo ser el mismísimo Francisco de Borja, futuro jesuita y General de la Compañía, el responsable del cruce de caminos entre el padre Bertrán y la abulense. ${ }^{9}$ Porque el noble conocía muy bien ésta. ${ }^{10} \mathrm{Y}$ aún más a aquel (Callado Estela 2010: 48 y ss.). Con fray Luis y el padre Juan Micó había fundado el todavía duque, el año 1548, el convento de Santa Cruz, en el marquesado de Llombai, tierra de moriscos a quienes convenía evangelizar (Callado Estela 2011 y 2013). ¿Fue el jesuita, en sus pláticas espirituales, quien dio a conocer a la madre del Carmelo la fama del religioso...?

En cualquiera de los casos, en 1561 -hecho lo propio con otro santo varón, como el padre Pedro de Alcántara, uno de sus padres espirituales-Teresa se decidió a escribir al dominico, por assegurarse más, sabiendo que en Valencia resplandecía el santo padre frai Luis Beltrán, de la orden de santo Domingo, decorado ya con la honra de beatificado i que era mucha la opinión de santidad i prudencia que dél tenía toda España, le consultó [...], diziéndole con llaneza todo lo que hasta allí le avía pasado con Dios i con su confessor. ${ }^{11}$

8 Cuestión que formuló por vez primera -en un trabajo tan interesante como breve-, Robles Sierra (1981). En él se basaría Esponera Cerdán (2014).

9 Véase nota 4.

10 Véanse Mújica (2011), E. Callado Estela (2010) La Parra López (en prensa).

11 Véanse F. de Santa María (1644: 128), el Lib. I, cap. XXXVI Renuévansele los mandatos del Señorpara la fundación. Consulta

SCRIPTA, Revista internacional de literatura i cultura medieval i moderna, núm. 7 / juny 2016 / pp. 150-159 


\title{
Emilio Callado. Teresa y Luis, Luis y Teresa. Dos santos en tiempos recios
}

La carta en cuestión no ha sido localizada hasta ahora, bien porque el mismo destinatario la hiciera desaparecer - «porque como podía ceder en alguna gloria del santo, la devió esconder, como lo hazía en todas las cosas que podían redundar en alabança propia»- tal como indica Vidal y Micó (1743: 106)-, o se perdiera entre sus devotos. ${ }^{12}$ Muy posiblemente expresara en ella la Santa sus afanes reformistas y revelaciones divinas, sintiéndose «mandada del Señon», como referiría en tantas otras ocasiones. Sin ir más lejos, aquella en que

\begin{abstract}
Habiendo un día comulgado, mandóme mucho Su Magestad lo procurase con todas mis fuerzas, haciéndome grandes promesas de que no se dejaría de hacer el monesterio; y que se serviría mucho en él; y que se llamase San Josef; y que a la una puerta nos guardaría Él y Nuestra Señora la otra; y que Cristo andaría con nosotras y que sería estrella que diese de sí gran resplandor; y que aunque las relisiones estaban relajadas, que no pensase se servía poco en ellas; que qué sería el mundo si no fuese por los relissiosos; que dijese a mi confesor esto que me mandaba y que le rogaba Él que no fuese contra ello ni lo estorbase. ${ }^{13}$
\end{abstract}

Sí ha llegado hasta nosotros, afortunadamente, la respuesta de fray Luis Bertrán, escrita antes de marcharse a las Índias para llevar allí el Evangelio, en su incansable cruzada apostólica, en 1562, y mientras Teresa andaba atormentada por la fundación de San José de Ávila. De su contenido, con tono animoso y profético, se infiere que el religioso tardó algunos meses en componerla, después de someter el asunto a la oración. He aquí la misiva:

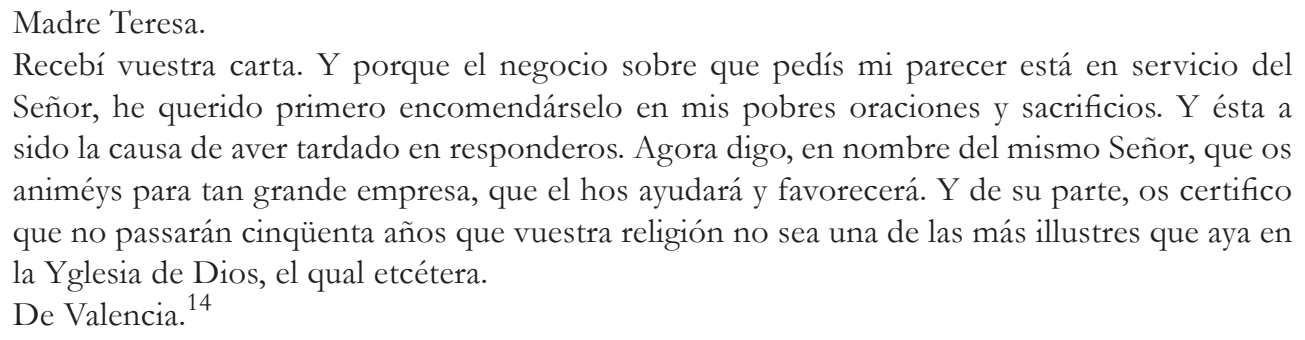

a los padres frai Pedro de Alcántara i frai Luis Beltrán.

12 Dice V. J. Antist, a este respecto, que a la muerte del religioso y tras el saqueo de sus objetos personales por parte de sus fieles, que «pidiendo [...] o algún libro o papel o carta suya, hasta tomar de las vendas [...]. Y esto han hecho no solamente los seglares, sino ecclesiásticos y aún prelados y señores de título, no sólamente los que se hallaron presentes a su entierro, sino los ausentes, pidiendo por cartas algunas de aquellas cosas. Y aún los mismos religiosos, que toda su vida le habían tratado, y por consiguiente si no fuera tan amigo de Dios no había de hacer tanto caso de sus cosas» (Citado en Robles Sierra 1981: 124).

13 Véase el cap. XXXII, «En que trata cómo quiso el Señor ponerla en espíritu en un lugar de el Infierno que tenía por sus pecados merecido. Cuenta una cifra de lo que allí se le representó, para lo que fue. Comienza a tratar la manera y modo como se fundó el monesterio, ahora donde está, de San Josef» del Libro de la Vida de Teresa de Jesús (1915: 268).

14 Lo reporta V. J. Antist (1583: ff. 66-67v), en el cap. 6, Del don de profecía y conocimiento de espíritus de que fue dotado este siervo de Dios. El texto -aunque con algunas variantes- lo ofrecerían también los biógrafos y editores de la ópera teresiana, basándose en el

SCRIPTA, Revista internacional de literatura i cultura medieval $i$ moderna, núm. 7 / juny 2016 / pp. 150-159 


\section{Emilio Callado. Teresa y Luis, Luis y Teresa. Dos santos en tiempos recios}

No hay constancia documental de nuevos intercambios epistolares entre el dominico y la abulense. Uno y otra, sin embargo, debieron de seguir profesándose un aprecio mutuo, que a la muerte de ambos heredaron sus hermanos de hábito. Pondríase de manifiesto durante sus respectivas beatificaciones.

Así, por ejemplo, el padre Esteban de Thous, prior del convento del Carmen de Valencia, doctor en Teología y catedrático de la Universidad de Huesca ${ }^{15}$, pronunció una panegírica prédica en memoria de fray Luis con ocasión de su primer paso a los altares en 1608. Sermón «tan lleno de erudición y predicado con tanto espíritu que a infinitos oyentes que tuvo los dexó hechos predicadores de sus alabanças». ${ }^{16}$

Por su parte, en 1614, el padre Jerónimo Bautista de Lanuza, discípulo bertraniano y Provincial de Aragón de la orden de Predicadores, ${ }^{17}$ participó en las festividades homólogas celebradas por Teresa de Jesús en Zaragoza (Díez de Aux 1615: 154-184). Tres años después, como obispo de Barbastro, el mismo religioso pedía al papa Paulo V la canonización de la ya beata:

Es tan grande el affecto de devoción que tiene esta ciudad y diócesi con la beata Teresa de Jesús que cada uno confiessa ha recibido de mano de vuesa santidad un señalado benefficio en haver concedido a todas las personas ecclesiásticas licencia de rezarle officio, y a todos los sacerdotes de celebrarle missas; por el qual, assí en mi nombre como en el de todo este clero y pueblo, doy a vuestra santidad las gracias, rogando a nuestro gran Dios que oiga nuestras oraciones por la salud de vuestra santidad. Enciende esto tan valiente affecto para con la dicha virgen en los corazones de todos, que con summo desseo apetecen verla por mano de vuestra santidad con solemne canonización puesta en el número de los santos. Lo qual, postrado a los beatíssimos pies de vuestra santidad, no sólo en mi nombre, sino también de todo este clero y pueblo, con instancia y humildad supplico y pido. Para que los que tuvieren charidad con el exemplo desta virgen procuren mayores augmentos y queden convencidos los tibios; los quales, declinando a palabras de malicia y buscando escusas para sus pecados, proponiendo la fragilidad de nuestro tiempo, juzgan cassi impossible que oy se halle virtud perfecta y excellente espíritu. Y sin duda alguna que esta bienaventurada virgen, que floreció grandemente en la virtud del agradecimiento, recibiendo tamaño benefficio de mano de mano de vuestra santidad, alcanzará del omnipotente Dios ( lo qual también nosotros pedimos con humildad ) que guarde a vuestra santidad mucho tiempo con entera salud y le conceda felicíssimos años de vida. ${ }^{18}$

manuscrito 12763 de la Santa.

15 Conocido por su faceta homilética, de la que constituyen un buen testimonio el Sermón en las exequias del venerable padre maestro fray Juan Sanz (Valencia, 1608), el Sermón en las honras que hiž el convento de Nuestra Señora del Carmen de Valencia al venerable y devoto sacerdote mossén Francisco Gerónimo Simón (Valencia, 1608) y el Sermón en las fiestas que el convento de San Josef de religiosos carmelitas calzados de Valencia bizo a la beatificación de santa Teresa de Jesús (Madrid, 1615), entre otros, como reporta Ximeno (1747-1749, I: 332).

16 Puede verse en Gómez (1609).

17 Véanse Fuser (1648), Gómez García (1982) y Julve (1981).

18 Citado por Laureano Robles (1981: 126). El original, en latín, en Biblioteca de la Universitat de València, Varia 698,

SCRIPTA, Revista internacional de literatura i cultura medieval i moderna, núm. 7 / juny 2016 / pp. 150-159 


\section{Bibliografía}

Antist, V. J. (1583) Verdadera relación de la vida y muerte del padre fray Luis Bertrán, de bienaventurada memoria, Barcelona, Pablo Senescal.

Aviñó, B. (1623) Vita, virtú e miracoli del beato Luigi Bertrando, Roma, Alfonso Ciaccone.

Belda, M. (1802) Compendio de la vida del beato Juan de Ribera, Valencia, Joseph de Orga.

Busquets Matoses, J. (1683) Idea exemplar de prelados, delineada en la vida y virtudes del venerable varón el illustrísimo y excellentísimo señor don Juan de Ribera, Patriarca de Antioquia, arzobispo de Valencia, su virrey y capitán general, fundador del real colegio de Corpus Christi, Valencia, Convento de Nuestra Señora del Carmen.

Callado Estela, E. (2009) «Así en la Tierra como en el Cielo. El Patriarca Ribera y los santos», en E. Callado Estela (coord.), Curae et studii exemplum. El Patriarca Ribera cuatrocientos años después I, Valencia, Publicacions de la Universitat de València, pp. 301-337

- - (2010) «Amics en Crist. Les amistats santes de Francesc de Borja», en Estampes de santedat. Sant Francesc de Borja i els sants espanyols del seu temps, Valencia, Consorci de Museus de la Generalitat Valenciana, pp. 23-56.

- (2011) «En tierra de infieles. Fray Juan Micó y la fundación borgiana de Santa Cruz de Llombai», en E. García Hernán y $\mathrm{M}^{a}$. P. Ryan (eds.), Francisco de Borja y su tiempo : politica, religión y cultura en la Edad Moderna, Valencia/Roma, Albatros / Institutum Historicum Societatis Iesu, pp. 223-235.

—_. (2013) «El dominico fray Juan Micó. Reforma y predicación en el siglo XVI», en E. Callado Estela (coord.), Valencianos en la Historia de la Iglesia IV, Valencia, Facultad de Teología San Vicente Ferrer, pp. 179-227.

- (ed.) (en prensa) Viviendo sin vivir en mí. Estudios en torno a Teresa de Jesús en el Vo Centenario de su nacimiento.

Callado Estela, E. \& Esponera Cerdán, A. (2008) «San Luis Bertrán, un dominico en tiempos de Reforma», en E. Callado Estela (coord.), Valencianos en la Historia de la Iglesia II, Valencia, Facultad de Teología San Vicente Ferrer, pp. 137-185.

Cárcel Ortí, V. (2001) Historia de las tres diócesis valencianas, Valencia, Generalitat Valenciana.

Cepari, V. (1624) Ristretto della vita del beato padre Francesco Borgia, Roma, Herede di Bartolomeo Zannetti.

f. 523. El también dominico fray Ildefonso Batista, ratificaría la devoción teresiana del padre Lanuza, quien «a santa Teresa de Jesús amó con particular affecto, y alguna vez afirmó, siendo obispo de Barbastro, que havía muchos años que no se havía acostado noche alguna sin haver leydo alguno de sus libros». Biblioteca de la Universitat de València, mss. 801, f. 60 . 
Cienfuegos, A. (1702) La heroyca vida, virtudesy milagros del grande san Francisco de Borja, antes duque cuarto de Gandia y después Tercero General de la Compañia de Jesús, Madrid, Bernardo Peralta.

Cubí, M. (1912) Vida del beato Juan de Ribera, Barcelona, H. de Viuda Pla.

Dalmases, C. (1983) Elpadre Francisco de Borja, Madrid, Ed. Católica.

Díez de Aux, L. (1615) Retrato de las fiestas que a la beatificación de santa Teresa de Jesús bizo Zaragoza, Zaragoza, Juan de Lanaja y Quartanet.

Escrivá, F. (1612) Vida del illustríssimo y excelentíssimo señor don Juan de Ribera, Patriarca de Antiocbia y arzobispo de Valencia, Valencia, Pedro Patricio Mey.

Esponera Cerdán, A. (2014) «Teresa de Jesús, Luis Bertrán y la reforma carmelitana», Teología Espiritual, LVIII, pp. 349-365.

Fuser, J. (1648) Vida del venerable apostólico varón don fray Gerónimo Batista de Lanuza, de la orden de Predicadores, obispo de Barbastro y de Albarracin, Zaragoza, Pedro Lanaja.

García Hernán, E. (1999) Francisco de Borja, Grande de España, Valencia, Institució Alfons el Magnànim.

Gómez, V. (1609), Los sermones y fiestas que la ciudad de Valencia bizo por la beatificacion del padre san Luys Bertrán, Valencia, Juan Chrysóstomo Garriz.

Gómez García, V. T. (1982) «Jerónimo Bautista de Lanuza, o.p. (1553-1624), discípulo de san Luis Bertrán», en Corrientes espirituales en la Valencia del siglo XVI (1550 - 1600), Valencia, Facultad de Teología San Vicente Ferrer, pp. 267-287.

Huerga, A. (1963) «I domenicani nella vita e nella riforma di S. Teresa», Rivista di Vita Spirituale, 27, pp. $458-474$.

Huerta, A. (1669) Historia y admirable vida del glorioso padre san Pedro de Alcántara, Madrid, Juan García Infançón.

Inciarte, E. (1962) «Santa Teresa y la orden dominicana (Revisión y glosa de los textos teresianos)», Teología Espiritual, VI, pp. 443-468.

Jesús, T. de (1915) Obras. Libro de la Vida. S. de Santa Teresa (ed.), Burgos, Tipografía de El Monte Carmelo.

- (1951) Obras completas. E. de la Madre de Dios, O. del Niño Jesús y O. Steggink (eds.), vol. I, Madrid, BAC.

Julve, V. (1981) «Intimidad de san Luis Bertrán con fray Jerónimo Batista de Lanuza», Cuadernos san Luis Bertrán, 9, pp. 389-394.

La Parra López, S. (en prensa) «Francisco de Borja en el espejo de Teresa de Jesús (Vidas paralelas unidas por la modernidad )»

Loarte, L. (1672) Historia de la vida, milagros y virtudes del glorioso san Luis Bertrán, Madrid, Francisco Sanz. 
Martín, F. (1909) Santa Teresa de Jesús y la orden de Predicadores, Ávila, A. Jiménez.

Mújica, B. (2011) «Encuentro de Santos: Francisco de Borja y Teresa de Jesús», en E. García Hernán y $\mathrm{M}^{a}$. P. Ryan (eds.), Francisco de Borja y su tiempo : politica, religión y cultura en la Edad Moderna, Valencia/Roma, Albatros / Institutum Historicum Societatis Iesu pp. 745-754.

Nieremberg, J. E. (1644) Vida del santo padre y gran siervo de Dios el beato Francisco de Borja, tercero General de la Compañia de Jesús y antes duque quarto de Gandia, Madrid, María de Quiñones.

Procesos (1983) Procesos informativos de la beatificación y canonización de san Luis Bertrán. Introducción y transcripción de A. Robles Sierra. Traducción de M. A. Llop Catalá, Valencia, Provincia Dominicana de Aragón.

Robres Lluch, R. (1960) San Juan de Ribera. Patriarca de Antioquia, arzobispo y virrey de Valencia 15321611, Barcelona, Juan Flors .

Ribadeneyra, P. (1592) Vida del padre Francisco de Borja, que fue duque de Gandia y después religioso y tercero General de la Compañía de Jesús, Madrid, P. Madrigal.

Robles, L. (1981) «El padre Lanuza y santa Teresa», Cuadernos San Luis Bertrán, 3, pp. 125-127

Robles Sierra, A. (1973) «Correspondencia de san Luis Bertrán», en San Luis Bertrán. Reforma y Contrarreforma española, Valencia, Gráficas Soler, pp. 335-371.

—_. (1981) «San Luis Bertrán y Santa Teresa de Jesús», Cuadernos San Luis Bertrán, 3, pp. 122-123.

Roca, J. B. (1608) Historia verdadera de la vida y milagros de san Luis Bertrán, bijo de la ciudad y convento de Predicadores de Valencia y de su beatificación por nuestro santo padre Paulo V, Valencia, Juan Crisóstomo Garriz.

Saborit, V. (1651) Historia de la vida, virtudes y milagros del beato Luis Bertrán, de la orden de Predicadores, Valencia, Bernardo Nogués.

San Bernardo, I. de (1667) Chrónica de la vida admirable y milagrosas haçañas de el admirable portento de la penitencia san Pedro de Alcántara, reformador de la orden seráfica, fundador de los descalços de nuestro seráfico padre san Francisco, confessor y padre espiritual de santa Teresa de Jesús y su coadjutor, Nápoles, Geronimo Fasulo.

Santa María, F. de (1644) Reforma de los descalcos de Nuestra Señora del Carmen de la primitiva observancia. Tomo primero, Madrid, Diego Díaz de la Carrera.

Santa María, J. (1619) Vida, excelentes virtudes y obras miraculosas del santo fray Pedro de Alcántara, fundador de la Provincia de San Joseph de los descalcos de la orden de san Francisco, Madrid, Viuda de Alonso Martín.

Schotto, A. (1596) De vita Francisci Borgiae, Roma, Aloysium Zannettum.

Suau, P. (1963) Historia de San Francisco de Borja, Zaragoza, Hechos y Dichos.

Vidal y Micó, F. (1743) Historia de la prodigiosa vida, virtudes, milagros y profecías del segundo Ángel del 
Emilio Callado. Teresa y Luis, Luis y Teresa. Dos santos en tiempos recios

Apocalipsis y apóstol valenciano de las Indias Occidentales san Luis Bertrán, Valencia, Joseph Tomás Lucas.

Ximénez, J. (1798) Vida del beato Juan de Ribera, Valencia, Josep de Orga.

Ximeno, V. (1747-1749) Escritores del reyno de Valencia, 2 vols., Valencia, Josep Esteban Dolz.

Yepes, D. de (1606), «Prólogo. De la grande aprovación que hubo siempre de la santidad y perfeción de vida de la madre Teresa de Iesús», en Vida, virtudes y milagros dela bienaventurada virgen Teresa de Jesús, madre y fundadora de la nueva reformación de la orden de los decalços y descalças de Nuestra Señora del Carmen, Zaragoza, A. Tavanno, s.p. 